\title{
RETRACTION
}

\section{Aberrant methylation profile of human malignant mesotheliomas and its relationship to SV40 infection}

M Suzuki, S Toyooka, N Shivapurkar, H Shigematsu, K Miyajima, T Takahashi, V Stastny, AL Zern, T Fujisawa, HI Pass, M Carbone and AF Gazdar

Oncogene (2014) 33, 2814; doi:10.1038/onc.2014.100

Retraction to: Oncogene (2005) 24, 1302-1308; doi:10.1038/ sj.onc.1208263; published online 13 December 2004

This paper is retracted due to image duplication involving scientific misconduct. The Internal Review Committee at UT Southwestern Medical Center, Dallas has found evidence that Figure $2 \mathrm{a}(\mathrm{p} 16 \mathrm{U})$ in the published manuscript was duplicated and manipulated in Figure 1 in the paper by M Suzuki, H Shigematsu,
N Shivapurkar, J Reddy, K Miyajima, T Takahashi, AF Gazdar, and EP Frenkel, Methylation of apoptosis related genes in the pathogenesis and prognosis of prostate cancer. Cancer Lett 2006; 242(2): 222-230. All authors of this paper agree to this retraction except for $A L$ Zern, who could not be reached to comment on the retraction. 